IHR

35,2

\section{2}

Received 14 September 2020 Revised 25 January 2021 Accepted 26 January 2021

\title{
Pivot! How the restaurant industry adapted during COVID-19 restrictions
}

\author{
Cortney L. Norris, Scott Taylor Jr and D. Christopher Taylor \\ Conrad Hilton College of Hotel and Restaurant Management, University of Houston, \\ Houston, Texas, USA
}

\begin{abstract}
Purpose - The purpose of this systematic review is to highlight some of the business model changes restaurants, bars and beverage producers undertook to modify their operations in order to not only stay in business but also to better serve their employees and communities during the COVID-19 crisis.

Design/methodology/approach - An analysis was conducted on 200 industry articles and categorized into three major themes: expansion of take-out/delivery, innovative practices, and community outreach/corporate support, each are further subdivided into additional themes. The systematic review is further supported by personal interviews with industry professionals.

Findings - This research finds that there were many different approaches used in adjusting business models in response to the dining restrictions put in place due to COVID-19. From these approaches, themes were developed which resulted in uncovering some suggestions such as developing contingency plans, being flexible and creative, eliminating menu items, investing in a communication platform and getting involved with local government. In addition, some practices operators should be mindful of such as selling gift cards and starting a crowdfund.

Research limitations/implications - This research provides a systematic analysis of business model changes that occurred due to COVID-19 dining restrictions. Researchers can use this information as a guide for further analysis on a specific theme introduced herein.

Practical implications - This research offers several practical implications which will assist the industry should another similar event occur in the future. The systematic analysis describes and documents some suggestions as well as practices to be mindful of in preparing contingency plans for the future.

Originality/value - This research documents an unprecedented time for the hospitality industry by examining how restaurant, bar and beverage producers around the country responded to COVID-19 restrictions. Distilling the multitude of information into succinct themes that highlight the business model changes that occurred will aid future research as well as operators.
\end{abstract}

Keywords COVID-19, Hospitality industry, Restaurant response, Food and beverage

Paper type Research paper

\section{Introduction}

In the past 20 years, the United States has been faced with a multitude of crisis situations ranging from terrorist attacks to natural disasters and viral epidemics. None of which have simultaneously upended numerous industries, caused massive layoffs and closures like the most recent COVID-19 pandemic. A pandemic is described as a new disease that emerges and spreads around the world, and to which most people do not have immunity (WHO, 2010). Pandemics can cause economic damage in multiple ways such as short-term fiscal shocks and longer-term negative impacts to economic growth (Madhav et al., 2017). An economic shock to one country quickly spreads to others due to financial linkages and increased trade associated with globalization (Lee and McKibbin, 2004).

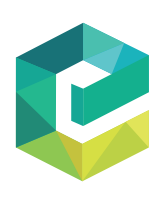

International Hospitality Review Vol. 35 No. 2, 2021 pp. $132-155$ Emerald Publishing Limited $2516-8142$ DOI 10.1108/IHR-09-2020-0052
(C) Cortney L. Norris, Scott Taylor Jr and D. Christopher Taylor. Published in International Hospitality Review. Published by Emerald Publishing Limited. This article is published under the Creative Commons Attribution (CC BY 4.0) licence. Anyone may reproduce, distribute, translate and create derivative works of this article (for both commercial and non-commercial purposes), subject to full attribution to the original publication and authors. The full terms of this licence may be seen at http:// creativecommons.org/licences/by/4.0/legalcode 
In addition, pandemics can cause behavioral changes such as fear induced aversion to public gathering places or places of work which are a primary cause of the negative impact to economic growth during and after an outbreak (Madhav et al., 2017). It is estimated that the global economic loss of the SARS outbreak in Asia represented $\$ 40$ billion in 2003 (Lee and McKibbin, 2004). A point of optimism is offered from historical data that shows economic markets rebound quickly from health scares, as seen with the S\&P growing $14.59 \%$ following SARS and 5.34\% after Ebola (Everett, 2020).

The hospitality industry which relies on tourism, events and eating meals away from the home is one of the most hard-hit during pandemics. Since the beginning of the COVID-19 pandemic in the United States hotels have lost more than $\$ 46$ billion in room revenue and 4.8 million hospitality and leisure jobs (AHLA, 2020). The restaurant industry has laid off or furloughed more than eight million employees and is expected to lose $\$ 240$ billion by the end of 2020 (NRA, 2020).

For restaurants located in areas prone to natural disasters, emergency preparedness and contingency plans are a must. Prior to the COVID-19 pandemic, restaurant emergency preparedness of this nature was unprecedented, thus it is essential to study response from the industry in order to be better prepared with contingency plans should another pandemic or similar event occur in the future. The purpose of this systematic review is to highlight some of the business model changes that restaurants, bars and beverage producers undertook to modify their operations to not only stay in business but also to better serve their employees, communities, and those in need during the COVID-19 crisis. Furthermore, aiming to provide suggestions based on the findings which could be utilized by operators in the future.

\section{Methodology}

A systematic review is a comprehensive summary of primary research that attempts to identify, select and synthesize all related evidence to provide an unbiased overview of the selected topic (Harris et al., 2014). A systematic review was selected for this study to understand and synthesize into themes the multitude of responses from restaurant operators during the initial onset of regulations aimed at quelling the spread of COVID-19.

This study will focus on the initial onset of government mandates to close restaurants, bars and beverage producers for on/own-premise sales through the relaxation of those mandates as states began to emerge from quarantine, March 15 through May 15, 2020. A variety of publications were selected to understand the industry's response including: National Restaurant Association, Nation's Restaurant News, Forbes and Spirits Business. Additionally, five major cities featured on Eater.com were selected, due to their prevalence in the restaurant industry, New York, Chicago, Washington D.C., Los Angeles, Houston and San Francisco. All articles that were published between March 15 and May 15 from each of the selected publications websites were reviewed and selected based on their applicability to the aim of the research. Applicability was determined either from the title of the article or from a precursory scan of the article's contents, as a result a total of 294 articles were collected. Upon complete review of the articles, 94 were removed from further analysis because they focused on overall effects to the industry or statistics relating to COVID-19 and not on specific business model changes that were implemented.

The remaining 200 articles were reviewed again, and each business model change mentioned was written down, if the specified change was the same as one previously mentioned a tally mark was noted next to the corresponding topic. Many of the selected articles dealt with a few restaurants and covered similar yet distinct changes, resulting in one article generating several different changes being noted. This stage of analysis resulted in 200 articles being sorted into 27 different categories of implemented changes. These 27 categories were then analyzed again and condensed down to 14 categories based on 
IHR

35,2

134

similarity. For instance, articles dealing with pop-up markets and selling packaged meal items to grocery stores were combined, articles that discussed family meals and meal kits were combined and articles that discussed selling gift cards were combined with those that dealt with selling merchandise. The categories were then analyzed again and sorted into three major overarching themes that encompassed their breadth and include, expansion of take-out operations, innovative practices and community outreach/corporate support.

Following the systematic review of articles, a request for interviews was sent to industry professionals/businesses identified in that articles as having implemented one or more of the identified practices. Interview questions were developed by the researchers based on information garnered from the systematic review, the aim was to provide deeper understanding of the operational changes and the thought processes behind the decisions. A total of 34 interview requests were sent out, 13 each to those categorized into the expansion of take-out operations and innovative practices themes and 8 to those categorized into the helping the community outreach/corporate support theme. A total of nine responses were received, five responses were from businesses who had implemented more than one of the changes noted in the systematic review, representing a $26.5 \%$ response rate. Those that responded and declined to accept cited that they were too inundated with maintaining operations to participate. Interviews were carried out primarily over email at the request of the interviewees and in one instance a phone call was possible, which was recorded and transcribed by the first author. Quotes from interviews as well as direct quotes from the industry articles were selected to provide a richer understanding of the identified themes and sub-categories.

\section{Results}

The systematic review of industry articles that focused on the response and changes implemented by the restaurant industry due to COVID-19 restrictions resulted in three overarching themes. Each major theme is broken down into several sub-themes, Table 1 provides a breakdown of the major themes as well as sub-themes identified during the systematic review. Each is discussed in more detail next.

\section{Expansion of take-out operations}

As restrictions to quell the spread of COVID-19 began being implemented, specifically closing restaurants for dine in operations, restaurant owners and corporations across the country varied in response. For some restaurants, the decision was much easier than for others, fastfood, fast-casual, and casual dining restaurants were already acquainted with to-go/carry-out

Table 1.

Major themes and sub-themes
Expansion of take-out operations (82 Innovative practices (89 articles)

(1) Adjusted operating schedule and employee roles

(2) Re-imagined dining rooms

(3) New/limited/rotating menu items

(4) Online ordering and third-party delivery

(5) Collaboration

(6) Communication with customers and employees articles)

Community outreach/ Corporate support (63 articles)
(1) Pop-up markets/grocery store partnership
(2) Family meals/meal kits
(3) To-go cocktails/beer/wine
(4) Food with a side of fun
(5) Additional revenue streams
(1) Community/employee outreach
(2) Production of hand sanitizer
(3) Corporate donations/grants and funds


operations and the pivot happened seamlessly (Luna, 2020a). For others such as fine dining, where delivery or carry-out were never a part of their business model, the task seemed insurmountable. While others opted to close completely, amongst them Union Square Hospitality Group, CraftWorks Holdings (Luna, 2020b) and many other smaller chains (Adams, 2020), citing reasons such as to protect their employees and to take social distancing as far as possible to stop the spread of the virus (Hiatt, 2020d; Plumb, 2020a; Selvam, 2020a).

Many restaurants that opted to make the pivot to delivery/carry-out only models eventually ended up closing temporarily, the most often cited reason was for the safety of their employees and customers alike (He, 2020b). First Watch CEO, Chris Tomasso noted that the primary motivation for closing their restaurants was employee safety and easing the burden on those that chose to continue working (Ruggless, 2020c). Yet, others expressed they were outmatched as Johnny Nunn of Verdigris says "I'm a cook. I'm not qualified to make decisions about people's wellbeing in the face of a crisis" (Feldmar, 2020).

Of those that successfully maneuvered their operations to carry-out/delivery only operations, a variety of reasons were provided, most often citing the desire to keep employees working and to support their suppliers, especially the farmers whose products would otherwise go to waste (Krupnick, 2020; Thorn, 2020a). Of the articles collected, 82 dealt with the shift in operations towards carry-out and delivery expansion, from these articles several themes presented themselves including: adjusted operating schedule and employee roles, reimagined dining rooms, new/limited menus, online ordering and third-party delivery, collaboration and lastly communication with customers and employees.

\section{Adjusted operating schedule and employee roles}

To comply with social distancing requirements as well as to meet shifting demands some restaurants found it helpful to adjust their operating schedules and employee roles. Jessica Pounds of Moo Creamery in California shifted to a 24-h operating schedule to minimize the number of employees in the restaurant at one time. This new schedule allowed food prep to be done overnight and service operations to take place during prime business hours. The move helped in creating safe social distancing and limited human contact while maintaining business operations (Sprayregen, 2020). Others opted to use staggered shifts for employees (Canavan Dixler, 2020) or limit hours of operation, moving from a 24-h operation to hours that would capture the most business and allow more time for deep cleaning and sanitization of public spaces and touch points (Fortney, 2020). Some found that their location dictated a change in schedule, those located in downtown areas that relied on office workers for a steady lunch rush, were without a rush when most office buildings closed (Adams, 2020).

Most restaurants featured in the articles, had to furlough employees, or allowed employees to choose to work or not which in some cases dictated a shift in operating schedule (Luna, 2020g; Troitino, 2020; Sprayregen, 2020). It also meant re-evaluating the roles of the employees that were willing to work. Barry Sorkin, cofounder of Smoque BBQ in Chicago used his employees who previously worked catering events as runners in the restaurant to handle the influx of curbside pickup orders (Maynard, 2020c). Shaun Garcia of Soby's retained servers by changing their jobs to delivery drivers, allowing them to nurture their relationships with their customers (Thorn, 2020b). Hosts became phone operators handling the incoming phone calls for carry-out orders and servers work a packaging line to ensure each order was accurate and complete. The key being to find a new role for everyone that wanted to continue working and an operating schedule that allowed for the safety of employees and optimal sales volume.

\section{Re-imagined dining rooms}

When restaurants no longer had customers dining in, the now empty dining room space could be re-imagined and used to assist in the new socially distant business operations. Tables that 
IHR

35,2

once were used for seating guests were now home to stacks of to-go containers or re-arranged as a packaging and distribution line (Maynard, 2020c). In some cases, to create more social distance amongst kitchen employees, prep work was moved from the kitchen to the dining room (Sprayregen, 2020). Joe Kyaw Thura Sein, Chef and Owner of Karaweik in San Francisco noted that his team was working to convert the dining room to maximize physical separation between employees, delivery persons and customers picking up orders (Zimmerman, 2020). Some restaurants converted the dining room into a pop-up market to provide pantry staples to the community (Canavan-Dixler, 2020).

Empty dining rooms also meant parking lots that were once full of cars also now sat empty and Michael Herrera of Mama Kat's in San Diego recognized an opportunity (Westfall, 2020). He turned the parking lot into a new socially distant dining area. Customers simply reserve a spot on the website and are encouraged to bring their own chairs, games, blankets and experience the parking lot picnic while enjoying Mama Kat's full menu (Westfall, 2020). The closure of in-house dining provided the opportunity for restaurants to re-imagine their dining rooms and other empty spaces in ways that helped to maximize their productivity and efficiency for the new preferred method of food service, delivery/carry-out.

\section{New/limited/rotating menu items}

With the increase in carry-out and delivery and in some cases a reduced work force, restaurants had to also re-think menu items. In an interview with Agricole Hospitality Group, which operates six restaurants in Houston, director of operations Bryan Davis said "the first consideration was to deplete inventory that was on hand and not spend extra money bringing in more items and as a result menu's changed daily, the next strategy was to order and make items that were popular, profitable and could be cross utilized and cutting out items requiring high labor and had a low shelf life" (B. Davis, email, April 5, 2020). At Beard and Belly in Chicago, partner Andrew Barbera indicated changes to the menu that included dropping French fries as a side to burgers as they do not travel well and to ensure the food experience is still up to par with customer expectations (Waxman, 2020c). The elimination of fried food from many menus is a prevalent theme that emerged across numerous articles (Luna, 2020g; Thorn, 2020e; Waxman, 2020c). Other restaurants focused on customer demand and shifting accordingly (Warerkar, 2020d) or select favorites and seasonal specials (Kravtiz Hoeffner, 2020). Bryan Davis of Agricole Hospitality Group said, "trying to provide the entire menu for to-go concepts was inefficient" and said, "we also tried to adhere to our normal standard of presentation we do in house for to-go" and found that "spending all that time trying to separate every dish, sauce, garnish led to a waste in packaging and labor" (B. Davis, email, April 5, 2020).

Some restaurants had to completely overhaul their menu which was not conducive to carry-out such as Emilie's in Washington D.C. which offered a communal-minded menu and transitioned into a Vietnamese takeout restaurant (Hiatt, 2020a). Golden Corral a buffet style restaurant transitioned to offering a rotating menu of comfort food to-go with items such as pot pie, meatloaf, and pot roast (Thorn, 2020a). The biggest transition had to be done by fine dining restaurants as tasting menus are not only expensive for the restaurant and consumer but also do not fare well in a take-out container (Pershan, 2020a; Thorn, 2020b; Troitino, 2020; Selvam, 2020b). EL Ideas, Phillip Foss noted the innovative tasting menu does not lend itself to takeout and shifted his focus to family meals but he "does not want his loyal customers to feel like he's compromising the creativity and quality that made EL Ideas a Michelin-starred restaurant” (Selvam, 2020b).

Alinea, a preeminent fine dining spot in Chicago known for its "immersive theatrical food performance" reinvented themselves into a carry-out operation serving dinner meals for less than $\$ 40$ (Turrow-Paul, 2020). Mark Canlis, owner of Canlis in Seattle said, "just because fine 
dining is what we're good at, it does not mean it's the right thing for anybody right now" (Troitino, 2020). Recognizing that the community wanted simple meals, Canlis transitioned his restaurant away from tasting menus to selling burgers, bagels, and dinner meals (Troitino, 2020). In an interview with Marie-Louise Friedland of Nancy's Hustle a fine dining restaurant in Houston in response to the question "how do you think carry-out only impacted your image/brand?" she replied "I think we were able to be very true to the Nancy's Hustle brand. Everything we did fit with what we did in the restaurant. We even created a side brand (Thicc Nancy's) that became incredibly popular" (M. Friedland, email, April 8, 2020). Troy Jorge, chef at Temporis a one Michelin star restaurant in Chicago said "honestly we do not believe it effected it (the brand) much really. All the restaurants at this level had to pivot and do what they could to make money and keep everyone employed while staying true to their brands. We believe that's what we did" (T. Jorge, email, June 28, 2020). For fine dining, the decision to pivot to a to-go operation came with trade-offs, the tasting menu, atmosphere, brand image and exclusivity they are known for gave way to the need to keep income flowing. Other fine dining establishments were not willing to make those trade-offs and instead shuttered their restaurants.

\section{Online ordering and third-party delivery}

In an effort to maintain social distancing and limit contact points, many restaurants launched online order platforms for their websites, expanded their third-party delivery partnerships and/or created drive-thru lanes. AlixPartners launched a survey to determine preferred method of food ordering during the pandemic finding that $43 \%$ of consumers said drive-thru is the preferred method followed by takeout and curbside pickup at 33\%, third-party delivery was the least popular, consumers said they would rather order directly from a restaurant (Luna, 2020g).

McDonald's in the past year has expanded third-party delivery to include DoorDash, Grubhub and UberEats and says that "delivery and mobile orders have become key channels for the business" (Luna, 2020f). With the only option for generating sales being delivery or carry-out, many corporate chains including Noodles and Co., Krystal, El Pollo Loco, Dickey's Barbecue Pit, Chipotle Mexican Grill, McDonald's, Applebee's, Panera Bread, IHOP and Wingstop all launched free delivery promotions (Ruggless, 2020d; Luna, 2020h). Wingstop Inc. saw same store sales increase $30 \%$ in April due to the free delivery promotion (Ruggless, 2020d). Many restaurants signed up for delivery partners not only as a way to feed the community but also to continue to employ restaurant workers (Elliott, 2020a).

The Coronavirus pandemic however is bringing to the surface the myriad of issues with third-party food delivery apps and forcing some restaurants to consider direct delivery. Chain restaurant, Noodles and Co. and even independent restaurants such as Mexicue in New York City launched direct delivery in March as it generates more revenue for the company by avoiding the commission fees from third-party delivery apps (Adams, 2020; Luna, 2020d). Mexicue found that in the first week of the direct delivery launch, orders increased drastically (Adams, 2020). The Uncaged Chefs in Washington D.C. found that doing direct delivery allowed them to hire their own drivers and therefore provide work for restaurant employees who were furloughed (Plumb, 2020c).

Some independent restaurants are using the down time to permanently pivot to fastcasual or to-go formats adding drive-thru lanes, walk-up windows for take-out and grab and go counters (Canavan Dixler, 2020; Luna, 2020g). A few corporate restaurant chains are opening to-go restaurant concepts, Buffalo Wild Wings opened a "go" model restaurant in May which featured a walk-up counter for orders and heated takeout lockers for those who ordered online (Ruggless, 2020d). P.F. Chang's and Bloomin' Brands restaurants are others that are also experimenting with to-go locations (Ruggless, 2020d). The decisions that are

\section{Restaurant industry during \\ COVID-19}


IHR

35,2 made will be individual to each operation based on location, market presence, capital, consumer demand and staffing levels. Delivery either through third-party app or direct through the restaurant has been a key to success for some restaurants.

\section{Collaborate}

The restaurant industry is one where friends are also rivals but when the pandemic began closing restaurants, many were at a loss for what to do or how to proceed and phoned a friend who was in the same situation. In Los Angeles' Thai Town, two dozen restaurants banded together to participate in a joint discount menu, offering menu items for $\$ 5$ each to entice customers to continue to support them during the shutdown (Elliott, 2020d). The restaurant community is very tight knit and staying in touch with others to find workable solutions or sharing of best practices could make the difference from one day to the next.

Some restaurants reached out to local favorites to bolster their offerings and combine efforts, allowing customers to order two great food options from one location. Beard and Belly in Chicago partnered up with Milwaukee-based pie maker Valeri Lucks of Honeypie Café to create a dual restaurant concept (Waxman, 2020c). Aaron Deal at The River and Rail in Virginia collaborated with a local coffee roaster that was closed due to the pandemic offering more value to customers and an opportunity to the coffee roaster (Thorn, 2020e). Jrink Juice Bar in Washington D.C. partnered with seven other restaurants and stores in the area (Ebner, 2020). Another collaboration in Washington D.C. brought together a popular barbecue restaurant and a local bookstore. The pop-up restaurant is offering delivery and encouraging the addition of a book with the meal so customers can support both businesses with one transaction (Hiatt, 2020c). Collaborations have created new sources of revenue for some businesses that were planning to close for the duration of the pandemic and succeeded in creating more value for consumers.

\section{Communication with customers and employees}

Communication is key to any successful operation, more so during a global pandemic where keeping your customers and employees informed of operational changes is critical. Social media platforms have helped many operators keep their customers up to date, posting daily specials/promotions or adjustments to hours of operation. Slapfish founder Andrew Gurel said they have been able to keep sales afloat by "remaining engaged in the community, listening to their customers and providing them what they need" (Thorn, 2020d). Underbelly Hospitality group in Houston in response to the question "how did you advertise to customers, what got the best response," noted they used their newsletter, social media and traditional media and that "social media response from our guests was very strong" (L. Brown, email, May 5, 2020). Bryan Davis of Agricole Hospitality Group stated, "established businesses did well with social media, newer businesses did better with guerilla advertising" (B. Davis, email, April 5, 2020).

Aaron Corsi, owner of $8^{\text {th }}$ Wonder Brewery and Distillery in Houston in a phone interview indicated, "continual, clear and honest communication" not just from the top down but back and forth communication with the employees as a best practice (A. Corsi, phone, April 3, 2020). Indiana based Patachou restaurants launched an open information site which has become the hub for the dissemination of critical information during this time (Hoover, 2020). Bryan Davis of Agricole Hospitality Group, in response to the question "if you could go back in time, what is one piece of advice you would give yourself?" he said, "I wish we had the ability to communicate with all employees across a single platform” (B. Davis, email, April $5,2020)$.

In addition to staying in contact with customers and employees, an open line of communication with local health and government officials has been vital for North Carolina 
based chef Ashley Christensen. She says, "we've been in constant contact with the governor and county reps; any time any document is produced, we have direct access to it, and we distribute it to a number of colleagues" (Feldmar, 2020). While many health and government agencies have not been able to provide all the answers restaurant owners seek, being the first to know what is coming next is vital during the initial phase of closures and regulations that are changing almost daily.

The expansion and in some cases addition of to-go style service has created new opportunities for restaurant owners and chefs to keep income flowing for not only the restaurant but also the employees whose livelihood depends on it. The themes that were uncovered in these articles shed some light on best practices and can be adjusted for any style of operation. Some restaurants went a step further and used innovative thinking to adjust their business models to ensure their survival during the pandemic.

\section{Innovative practices}

The closing of dining rooms and subsequent expansion and for some the addition of carry-out operations forced many restaurant owners to get creative and think outside of the box, not only with their menu's and spaces but also delivering an experience to their customers and providing value. Of the articles that were collected, 89 were sorted into the innovation theme and from these articles, five themes were prevalent throughout: pop-up markets/grocery store partnership, family meals/meal kits, to-go cocktails, food with a side of fun, and additional revenue streams.

\section{Pop-up markets/grocery store partnership}

In March when state governments were implementing new rules and closing dining rooms, grocery stores had an influx of bulk buying and were running low or out of stock on many staple items. The restaurant community found a way to solve three problems at once:

(1) grocery stores were out of stock on staple items (2) restaurant suppliers could not move large amounts of stock due to depleted demand (3) decreased sales. By turning dining rooms into pop-up corner markets, restaurants could continue to employ staff, support suppliers, create additional revenue and provide additional value to their customers by limiting the number of trips outside the home (Houck, 2020c; Petre, 2020; Yeo, 2020). Several large chain restaurants jumped on this trend including Panera, Subway, California Pizza Kitchen, Big Boy, Just Salad, Potbelly Sandwich Shop and Dog Haus, (Kelso, 2020b; Luna, 2020c; Redman, 2020; Thorn, 2020c). Andre Vener Co-owner of Dog Haus said, "grocery stores are being decimated, but restaurants and their distributors are sitting on so much product that it would be a shame to not find a way to still feed our guests" (Kelso, 2020b).

Many independent restaurants are also embracing this trend from Sandwich shops to award winning restaurants, using their network of suppliers to open their storerooms to customers and selling some popular restaurant items in packaged form. For many this includes dubbing the pop-up market with a new name, Olmstead in New York City, an exclusive fine dining restaurant is operating as Olmstead Trading Post, selling pre-packaged popular menu items as well as produce from local farms (Warerkar, 2020d). Ledger Restaurant and Bar in Salem, Massachusetts is operating as Ledger Basket offering a variety of prepared foods and pantry items (O'Brien Coffey, 2020c). The Grill in Washington D.C. transitioned to a pop-up market called The Butchery, offering marinated meats, prepared meals, staple ingredients, and sanitation supplies (Krishnamoorthy and Plumb, 2020). Phil Lempert a food and drink writer for Forbes, muses if this is the beginning of a new concept he dubs "restaurmart" (Lempert, 2020). Noting that grocery stores have moved into the foodservice arena as "grocerants" with success, offering fresh soup and salad or sushi bars, 
IHR

35,2 restaurants are now doing the same to create additional revenue and added convenience for customers (Lempert, 2020).

As such, grocery stores also reached out to local restaurants to supply pre-packaged take and bake meal options. Rouses Market in New Orleans is featuring popular dishes from local favorites, Commander's Palace, Saba, Ye Old College Inn and Bywater Bakery. Famous chefs have always had a home in grocery store aisles, "but it's much rarer for them to make fresh items to be sold in deli sections" (Maynard, 2020b). In Houston, grocery chain H-E-B and Kroger have also reached out to local restaurants to supply take and bake dishes. In an interview with Lindsey Brown of Underbelly Hospitality Group in Houston whose restaurants have been supplying take and bake items to grocery stores said the biggest considerations they had to make in executing this idea was "how to package the items - what materials to use and whether we could purchase enough. Also, which dishes would work best as take and bake items and how to get them delivered to each store" (L. Brown, email, May 5, 2020). The partnerships have been beneficial to restaurants who have been able to re-hire staff and capture revenue through this new channel of selling goods (Maynard, 2020b; McCarthy, 2020a, b).

\section{Family meals/meal kits}

Some restaurants specialize in family meal style of service, however for the greater majority family meals never had a place on their menu until COVID-19 forced many to re-evaluate their menu and offerings. Family meals have gained popularity as people are stuck at home and are losing motivation when it comes to cooking (Maynard, 2020d). Family meals provide the consumer with easy dinner solutions, something for the whole family instead of selecting individual items for each person, which also creates ease for the restaurant in preparation and packaging. In conjunction with the idea of limited/rotating menu items, Boka in Chicago, is offering three family meals per day including one vegetarian option (Selvam, 2020c). Different variations of the family meal exist as some restaurants are creating quarantine meals, with more of an individual person in mind. Mala Project in New York City is selling jars of their specialty items like five spice tofu or spicy beef sauce which can be paired with noodles, rice or dumplings and can create four to five meals at home (Kravitz Hoeffner, 2020). Similarly, Jack Rose in Washington D.C. is focusing on threecourse dinner packages for two (Plumb, 2020f).

In addition to prepared family meals, meals kits have become increasingly popular during quarantine. All the necessary ingredients are provided to be assembled and prepared by the individual and in some cases include video call conferences with chefs who provide guided instructions on how to assemble the contents to create the meal (Adams, 2020). For the budget conscious, fast food restaurants like Chick-fil-A, offering chicken parmesan meal kits and Shake Shack launched cook-at-home burger kits, selling more than 8,000 in the first twoweeks (Kelso, 2020c). Or for those seeking organic, locally sourced ingredients, Fat Rice in Chicago is selling $\$ 99$ meal kits which are designed to feed two adults and includes 30-min or less recipes with videos posted online for customers to follow along (Selvam, 2020e). Other operations are upping the ante by offering their meal kits along with rolls of toilet paper or hand sanitizer (Kravitz Hoeffner, 2020; Holmes, 2020).

For both those that have become a pop-up market or selling family meal/meal kits or perhaps a combination of both, subscription services were mentioned in multiple articles. The subscription service would allow customers to enroll in the program and receive a box of products each week from the restaurant. The Hitchcock Restaurant Group in Seattle created an 8-week subscription for produce boxes to support local farms (Flaherty, 2020). Officina in Washington D.C. launched Officina Provisions, a weekly subscription that includes butcher's boxes of meat, snacks, bread, and do-it-yourself meals (Krishnamoorthy and Plumb, 2020) 
and Zingerman's Deli launched ZingShare, a weekly subscription that includes ingredients from nine different Zingerman's concepts (Maynard, 2020d).

\section{To-go cocktails, beer and wine}

It is reasonable to assume that most restaurants do not have a package liquor license which would allow them to sell beer, wine, or distilled spirits to customers with their carry-out orders. Major regulation changes, the likes of which that have not been seen since the repeal of prohibition in 1933, were made allowing restaurants to sell and deliver alcoholic beverages to customers during the coronavirus shutdown (He, 2020a; Perhsan, 2020b). The regulation changes were an attempt to help bars and restaurants survive during these unprecedented times as alcohol sales as a national average make up 20-25\% of restaurant revenues and are one of the highest profit margin items (Thacker, 2019). Restaurants responded with alacrity launching all manner of to-go alcohol and cocktails utilizing everything from mason jars to heat-sealed bags to reach their consumers (Flaherty, 2020; He, 2020a; Thorn, 2020f).

Although regulations vary from state to state, all require that food must accompany alcohol sales. In Washington D.C., the regulation changes state that every 750 milliliters of spirit or quart of prepared cocktail must be accompanied by a prepared food item which is assembled, citing sandwiches, salads and smoothies as examples (Krishnamoorthy, 2020), leading some bar owners who do not usually serve food to get creative. Kingfisher is selling mayonnaise sandwiches with to-go beer and shot combos and Showtime Bar is packaging up peanut butter and jelly sandwiches wrapped in foil to meet the requirements (Krishnamoorthy, 2020). In New York, a bag of chips is enough to meet the food requirement and at Patent Pending each cocktail order automatically comes with a bag of chips and orders over $\$ 50$ get a free roll of toilet paper (Dai, 2020; He, 2020a). At Rocco's Tacos in West Palm Beach, Florida, owner Rocco Mangel noted that alcohol sales now accounted for $30 \%$ of all delivery sales (Thorn, 2020f) and Matt Krimm of Cinder BBQ in Washington D.C. said the decision to sell 375 milliliter bottles of bourbon for $\$ 20$ "helped bring in enough sales for the bar to maintain a semblance of its normal numbers" (Hiatt, 2020b).

Bars are also jumping on the kit craze, creating make at home cocktail kits. In Seattle, tropical themed bar, Navy Strength is staying on brand and serving spam sliders with tikithemed kits that contain a bottle of distilled spirit, mixers, garnishes, and recipes (Flaherty, 2020). Mint julep kits were sold at Jack Rose in Washington D.C. which included pebbled ice, powdered sugar, and fresh mint (Plumb, 2020f). At McClellan's Retreat, a "Zombie Survival Kit" was offered, which includes a pre-made zombie cocktail with four tiki glasses and garnishes (Krishnamoorthy, 2020). In addition, family meals/meal kits were quickly upgraded by the addition of cocktails, like margaritas and other favorites (Elliot, 2020e; O'Brien Coffey, 2020c).

To create more revenue, many bars and restaurants are selling off their collections of rare or expensive bottles to pay bills and employees during the shutdown. Jack Rose in Washington D.C. is selling off its acclaimed 2,700 bottle whiskey collection, some of the rarest going for $\$ 5,000-\$ 10,000$ a bottle (Plumb, 2020f). One cocktail bar Mister Paradise in New York city has transformed into Paradise Wine and Liquor store where customers can stock up on bottles of spirits, beer, or pre-mixed cocktails (Bellwood, 2020). Other creative ways bar owners are finding to support staff include removing all the of the dollar bills that adorn the walls of the bars (Jackson, 2020). Many bars have started opening to-go windows like Leyenda and 7B Horseshow Bar in New York City, where customers can walk up and order single serve or large format to-go cocktails (Bellwood, 2020; Ramirez, 2020a).

\section{Food with a side of fun}

Restaurants in many cases are not just a source of a good meal but also provide entertainment or an immersive experience. With dining rooms closed, the ability for a restaurant to provide

\section{Restaurant industry during \\ COVID-19}


IHR

35,2

entertainment or a quick escape from the day to day along with a meal became a major hurdle which some restaurant operators tackled with great success. CEO of Fresh Brothers Geoff Goodman indicated his company met the demand for food and an experience by offering a Jumanji movie bundle which included pizza, garlic knots and a promo code for a digital download of Jumanji: The Next Level (Glazer, 2020). Chuck E. Cheese, a staple in food entertainment for children launched new online entertainment options that accompany delivery and carry-out options (Glazer, 2020). In addition, they started afternoon fun breaks on their social media channels that feature songs, dances, coloring sheets and games for families to play together and birthday packs which include pizza, goody bags, party favors and games (Glazer, 2020; Thorn, 2020a). Furthermore, bakeries across the country are selling cookie decorating kits, stocked with baked cookies, sprinkles and frosting for parents and children to decorate together (Turrow-Paul, 2020).

Some bars and restaurants are focusing more on adult entertainment and employing the help of local out of work performance artists to deliver an experience. At Vampire Pizza in Los Angeles, your pizza is delivered by a vampire in full makeup and costume along with a narrative and a who done it type game (Elliott, 2020c). At The Darling in Chicago, a new to-go package features a four-course meal, flowers, candles, an LED projector, and a recorded musical performance and cabaret show put together by a local DJ and performance artists (Selvam, 2020f). At Pom Pom in Washington D.C. owner Carlie Steiner spiced up to-go wine by packaging the wine together in adult themes, such as the "Baby Makin' Collection." The package features three wines, "Quickie" Sauvignon Blanc, "Send Nudes" rosé and "Casual Encounters" Rhone-style blend and is rounded out with a romantic playlist and goodies (Plumb, 2020d).

Other bars are keeping it simple like Show time in Washington D.C. who is sending out packages of beer, whiskey, chips, sandwiches, and a record featuring local bands to bring the bar experience into their customers living room (Krishnamoorthy, 2020). McClellan's Retreat is selling a do-it-yourself house party kit which includes, beer, jello shots, red solo cups and ping pong balls (Krishnamoorthy, 2020). Others are encouraging virtual happy hours and hangouts (Krishnamoorthy, 2020) a beta site called goodhang and Virtual Dining Chicago allows users to choose a local bar or restaurant as a venue and invite friends to hangout and are encouraged to support the restaurant/bar through GoFundMe donations or gift card purchases (Turrow-Paul, 2020).

\section{Additional revenue streams}

Restaurants are no stranger to selling gift cards, however during the shutdown, gift cards became a lifeline for some, while others were not keen on the benefits. Many articles encouraged customers to support their local restaurant by buying gift cards (Maynard, 2020a; Plumb, 2020a; Waxman, 2020a) and some provided links to every restaurant offering gift cards (Valle, 2020; Warerkar, 2020e). Ravi Kapur owner of Liholiho Yacht Club in San Francisco recognizes that it is not a sustainable solution, but it is something that allows people to support the restaurant in some way and keeps the restaurant on life support (Valle, 2020).

Matt Krimm at Cinder BBQ noted that gift cards do not help everyone involved in the restaurant operation and instead encouraged donations to be distributed to laid off employees from meat processors to delivery drivers (Hiatt, 2020b). Reem Assil of Reem's California bakery noted that gift cards are a good short-term solution allowing rent or payroll to be paid but that it is not sustainable (Valle, 2020). Assil noted that the problem with gift cards is that while they provide cash flow now, when they all come in to be redeemed, there will be no cash flow coming from those customers when the restaurant is trying to get going again but all of the costs (Valle, 2020). Valeria Taylor owner of Loba Pastry and Coffee in 
Chicago, stopped selling gift cards after one day, noting that she did not have an existing gift card infrastructure and the anxiety of selling a gift card not knowing if her restaurant would be able to survive.

Other restaurants that did not have an existing gift card system in place turned to other sources of revenue. Xi'an Famous Foods in New York City focused on what they did have, great products and sold their Chile oil packs online, selling $\$ 27,000$ worth in one weekend (Valle, 2020). Reem Assil turned to selling merchandise instead of gift cards to boost sales as merchandise is a more secure cash flow option with fixed up-front costs (Valle, 2020). Articles that compiled all the restaurants selling merchandise and what was available for purchase were prevalent (Warerkar, 2020b; Waxman, 2020a). Restaurants around the country indicating selling things like egg cream scented candles, engraved cutting boards, graphic $t$-shirts, bottled sauces and condiments, tote bags and even onesies (Valle, 2020; Warerkar, 2020b; Waxman, 2020a).

Another source of revenue that many turned to support laid off employees and pay rent was using crowdfunding sites to fundraise. Like gift cards, there are split opinions on whether crowdfunding was a viable option for continuing operations or supporting employees. Washington D.C. bar Codmother saw rampant support from their die-hard customers and raised over $\$ 16,000$, allowing the bar to survive until to-go alcohol was approved in D.C. (Plumb, 2020e). Many restaurants hit their fundraising goals but were frustrated when it came time to withdraw and disperse the money (Shacknai, 2020). Multiple operators indicated that it could take up to two weeks to verify their identity and distribution methods before they were able to withdraw the funds (Shacknai, 2020).

In addition, Yelp and GoFundMe teamed up to help provide some relief for restaurants. GoFundMe automatically generated fundraisers for businesses listed on Yelp with five or fewer locations in areas hardest hit and was linked to the restaurant through the Yelp page (Pershan, 2020b). The problem was restaurant owners were not informed that this was happening and when they found the active fundraisers started in their name it was met with surprise, confusion, and anger (Pershan, 2020b). In response to criticism Yelp and GoFundMe changed the platform so restaurants could opt-into the program (Pershan, 2020b).

All these methods of innovative business model changes go above and beyond the simple expansion of take-out operations and create additional sources of revenue and value for the customer. Many restaurants also sought a way to give back to the community and their employees.

\section{Community outreach/corporate support}

Despite the uncertain current and future situation that many hospitality businesses are facing, many still embraced their altruistic nature and worked to alleviate the burden placed on others. The outpouring of support from hospitality and hospitality adjacent businesses was highlighted in 63 of the collected articles. There were three major themes present amongst these articles: community/employee outreach, production of hand sanitizer and corporate donations/grants and funds.

\section{Community/employee outreach}

In addition to large donations to grants or relief funds, many restaurants despite the bleak reality of their current situation are reaching out to their local community to provide assistance. Restaurant owners wanting to ensure their employees were taken care of in these unprecedented times did not have much to give except food and supplies. Those who decided to close their doors emptied their pantries and refrigerators, giving the food and supplies to their employees and local food banks (Houck, 2020b; McCarron, 2020). Others offered free or 
IHR

35,2

144

pay what you can meal kits and meals to employees and their families (Alarcón, 2020; Elliott, 2020b; Gibson, 2020a; Hoeffner Kravitz, 2020; Kelso, 2020a; Waxman, 2020b). In Washington D.C., a 13,000 square foot events space turned into a relief center to help service industry workers and local school children without access to school meals and operates solely on donations and volunteers from local restaurants and suppliers (Plumb, 2020b).

In addition to supporting the hospitality industry employees who were out of work and experiencing financial burdens, many restaurants also helped provide meals to medical staff at local hospitals who were putting in countless hours. In some cases, restaurants were contacted by health care facilities to provide meals, while others launched campaigns to feed healthcare workers. Hopdaddy Burger Bar developed a "pay it forward" campaign, where every burger purchased is a burger donated to a healthcare professional (Alarcón, 2020), Chipotle started a buy one, give one program and will donate a burrito to medical professionals when customers name their burrito 4HEROES (Luna, 2020e). Some owners offered customers the chance to donate money towards a meal or buy a meal for a healthcare worker at local hospitals (Selvam, 2020d). Still others despite their current situations are donating meals from their own resources. Wingstop and Taco Bell sent their food trucks to local hospitals to provide meals (Luna, 2020e; Ruggless, 2020a), and Pizza has distributed 25,000 pizzas to frontline medical workers (Luna, 2020e). Harvard Gardens in Boston is providing free bagged meals to Mass General Hospital (Louise, 2020) and Sweetgreen is delivering free salads and bowls to the hospitals in the cities they serve (Kelso, 2020a).

The outpouring of support is not just confined to healthcare employees, restaurants are providing meals to families who relied on school meals for daily sustenance for their children. Three Los Angeles based restaurants Gus's World-Famous Fried Chicken, Sebastien's Mediterranean Cuisine and Prime Pizza all launched programs to provide meals for vulnerable students and families (Chaplin, 2020). Bessou in New York City is donating a meal to a child in need for every meal purchased (Hoeffner Kravitz, 2020), and the Derossi Global Group is offering free school lunches in several of their lower Manhattan restaurants (Shin, 2020). During the pandemic, the restaurant industry showed great compassion for others and sought out ways to help in any way possible.

\section{Production of hand sanitizer}

Much like the restaurant industry, small and global distilleries facing their own burdens felt it was their duty to help their communities who were facing massive sanitizer shortages. The main ingredient in both distilled spirits and hand sanitizer is ethanol, which distillers already produce. To make hand sanitizer from ethanol requires the addition of hydrogen peroxide, glycerol and distilled water resulting in denatured alcohol (Houck, 2020a; O'Brien Coffey, 2020a). However, distilleries had a major hurdle to overcome when it came to producing hand sanitizer, a distiller's permit does not allow for the production of denatured alcohol and the production of hand sanitizer requires a special permit. In the United States, the Alcohol Tobacco Tax and Trade Bureau (TTB) who governs alcohol production, relaxed permit regulations to allow distillers to produce hand sanitizer if the distillery holds a valid beverage producer's permit (Carruthers, 2020b, 2020c).

In an interview with Liam Hirt, a co-founder of Circumstance Distillery in the United Kingdom said, "we worked on the principal that the clock was ticking and in a crisis, it would be easier to get forgiveness than permission" and "we eventually sorted out all the regulations. . .many-many forms, many-many hours on the phone" (L. Hirt, email, March 23, 2020). Circumstance Distillery was one of the first to begin producing sanitizer and received massive media attention in the UK. One by one distillers all around the globe began producing hand sanitizer to meet the growing demand. In an interview with Sarah Gifford at Gulf Coast Distillers in Houston, in response to the question "what was the primary motivation in the 
decision to produce hand sanitizer she said, "we knew we would be able to impact so many people's lives across the nation and that was reason enough to make it happen" (S. Gifford, email, April 27, 2020). Aaron Corsi owner of 8th Wonder Distillery in Houston said in an interview, "I get calls all day long from hospitals, fire stations, schools, police departments all looking to procure hand sanitizer" (A. Corsi, phone, April 3, 2020).

In addition to permits and regulations, distilleries had to source the required additional ingredients and decide how to package the new product. Pete Weiss at Lexington Brewing Company in response to the question "if you could go back in time, what is one piece of advice you would give yourself" he said "order more packaging day one. We had no idea what the real demand was for hand sanitizer, we had someone reach out seeking one million bottles for a large corporation. Of course, we were not able to meet that demand, but every hospital and sheriff's office has been ecstatic to received even a gallon or two, the need is huge right now" (P. Weiss, email, March 30, 2020). Throughout all the articles regarding hand sanitizer, the products were being sold or donated entirely to facilities in need. Sarah Gifford at Gulf Coast Distillery said "we are both donating and selling. We have donated over 3 million pounds of hand sanitizer, we also have bottles for sale in retail locations, we only sell enough to cover our production costs" (S. Gifford, email, April 27, 2020).

Collaborations exist amongst those working to supply hand sanitizer as well. In Massachusetts, a small distillery Deacon Giles did not have the means to produce enough ethanol to meet demand. Co-founder Ian Hunter reached out to former co-workers at Harpoon Brewery to see if he could use beer that was not going to be packaged to turn it into hand sanitizer. Other brewers in the area also donated beer that would not be sold or packaged to the effort (O'Brien Coffey, 2020b). Breweries and wineries around the world sitting on beer and wine that would not be sold were looking for ways to repurpose and followed suit, turning beer/wine over to distillers to make into ethanol and eventually hand sanitizer (O'Brien Coffey, 2020b; Ledsom, 2020). According to the Distilled Spirits Council of the United States, there are more than 700 distilleries in the United Sates producing hand sanitizer ("Distilleries Making Hand Sanitizer to Fight COVID-19," n.d.).

In addition to the small local distilleries all racing into action to produce sanitizer, the large spirits producers donated alcohol to pharmacies, laboratories, or manufacturing partners in order to produce sanitizer. Diageo, the world's largest distilled spirits producer donated two million liters of alcohol (Carruthers, 2020d), Bacardi pledged 1.1 million liters of alcohol (Carruthers, 2020e), William Grant and Sons switched production at three of its locations to create five million liters of ethanol (Kiely, 2020) and Pernod Ricard is providing 70,000 liters (Carruthers, 2020a).

\section{Corporate donations/grants and funds}

Corporate entities in the hospitality and hospitality adjacent industries showed support for those suffering financial crisis due to coronavirus in the form of donations to charitable enterprises aimed at providing relief. The largest and most notable contributions came from the distilled spirit industry and beverage distributors. At the end of March 2020, the Distilled Spirits Council reported that distilled spirits companies had accounted for more than $\$ 12$ million in support of COVID-19 relief efforts (Japhe, 2020). Chef Edward Lee and Maker's Mark in partnership with the LEE Initiative, created the Restaurant Workers Relief Program. Donations from Maker's Mark covered the costs for labor and supplies to turn restaurants into relief centers providing to-go meals and supplies to restaurant workers who have been laid off (Alarcón, 2020; Gibson, 2020).

Other relief efforts are being made to provide support to out of work employees, from New York City's Llama San, Llama Inn and Daniel Humm's Eleven Madison Park. These operations are gathering donations, targeting the cities wealthiest to bid on packages starting 
IHR

35,2

at $\$ 5,000$ including wine tastings, artwork, reservations at the exclusive Rao's, a five-course dinner for nine guests cooked by chef Humm, and even a jog with chef Humm through Central Park (Sutton, 2020). Union Square Hospitality Group (USHG) is also auctioning travel and food packages as well as a zoom cocktail session with Danny Meyer, acclaimed restaurateur, and author, to raise money for the employee relief fund (Warerkar, 2020c). Chick-fil-A and Starbucks each created $\$ 10$ million in grants and relief funds to help employees and their communities (Fantozzi, 2020; Luna, 2020e).

The coronavirus pandemic ushered in dark days for the hospitality and hospitality adjacent businesses, but that did not stop them for finding a way to give back to their communities in one way or another. Restaurants and distilleries big and small all found a way to provide needed grants/funds, food and/or supplies to their community and employees, showing the true altruistic nature of the hospitality industry.

\section{Discussion}

This study provides an overview of the multitude of business model changes that were undertaken by restaurants during the initial COVID-19 regulations. Given what was discovered by reviewing and categorizing these business model changes, there is no "one size fits all" approach to describe, however, there are several suggestions that can be of potential benefit for any similar future occurrences. The first is being aware of global or localized events which could cause disruption to business operations and getting ahead of the impending situation. In conjunction with that, having contingency plans in place and revisiting/updating that plan at least twice a year will be paramount. The contingency plan should include items such as (1) who will be responsible for what (i.e. labor relations, communication with government officials and guests), (2) protocols for dealing with the threat (i.e. social distancing in the dining room, sanitization schedule, implementing carry-out operations etc.), (3) a kit of supplies to aid in the transition such as face masks, sanitizer and signage (4) a record of what was done previously in similar situations and what worked and did not work and more importantly why.

Many articles suggested that there was not just one winning change that was made, but several and those changes required innovation and creativity. Even more pressing was that those who failed to change, failed. Suggesting that restaurant owners should make an educated guess about changes that will work for their specific business, implement the changes, and assess their effectiveness and continue to adjust or discontinue depending on the results. Those that were successful implemented many different changes and made several adjustments over the selected time frame or stopped immediately. It is important to try new things, but it also important to recognize when they are not working.

In situations like COVID-19, there are no certainties or guarantees, but to survive there must be a way to capture revenue and it requires flexibility and creativity. Flexibility in making adjustments and overcoming obstacles that may be standing in the manager's way to implementing key changes for operational success. Such as the bar owners who typically do not sell food, putting together sandwiches to sell alcohol to-go and keep their businesses afloat. Creativity led many restaurant owners to find new sources of revenue such as packaged sauces, to-go cocktails or merchandise and others found a way to create more value by providing entertainment options or becoming a one stop shop. Thinking outside the box of what is normal or expected is paramount in creating new or additional revenue streams. Creativity also led to innovative uses of space, creating more social distance between employees and increased efficiency. In addition, most restaurants made changes to their menus to reduce required prep work, eliminate items that do not travel well in packaging and save on costs of both packaging and items that are not cross 
utilized. It is important to make the menu work not only for customer satisfaction but also for controlling expenses in an uncertain environment. Focusing the menu on classic favorites or best sellers and eliminating one-off ingredients and dishes is an important takeaway.

Restaurant owners should also invest in a platform that allows them to communicate with all employees so that information can be disseminated easily and frequently. This was noted in several articles and in the interviews, getting one message out to employees simultaneously was helpful and stopped the spread of misinformation. This type of clear effective communication eased some of the burden on the mangers and owners who were juggling multiple problems at once. Additionally, it was evident that communication with customers was incredibly important so it would be advised to establish a social media presence or a central place that information regarding restaurant operations can be accessed by customers and updated frequently. Furthermore, restaurant owners should reach out to neighboring businesses and other restaurants. Several restaurant owners found success when they reached out to other business owners and even their suppliers who were all trying to decide which course of action to take, resulting in shared experiences, partnerships and collaborations that would not have otherwise existed. The review also made evident that following closely the government restrictions and getting involved in lobbying for regulation changes that benefit the business, for instance regulation changes that allowed to-go alcoholic beverages or production of hand sanitizer which helped buoy many restaurants/ distilleries and even the local community. Restaurant owners should get involved and be an active voice in the local government if only to make sure their voice is heard, and their issues fairly represented.

Many of the fine dining and award-winning restaurants who had to make the biggest changes which may have been considered "off brand" noted in many cases that they created side brands for their new endeavors. These side brands allowed them to be creative and flexible outside of what consumers expected of them in the actual restaurant. Side brands work similarly to co-branding, where the reputation established by one brand elevates the other. Establishing a side brand could work for other types of restaurants looking to experiment with something different than what their customers have come to know and love, creating new opportunities for growth and diversification.

Lastly, restaurant owners should find ways to give back to the community that supports them and continued to do so despite uncertain income, job retention and fear of the unknown. Throughout the review large and small restaurants found a way to show appreciation whether it be to local hospital staff working countless hours or to parents of school age children who lost school lunch programs. The restaurant industry is built on creating experiences and while customers could not come to the restaurants, many recognized that there were still plenty of opportunities to create those experiences and giveback at the same time.

There are some practices that were found in the articles that restaurant owners should be mindful of when implementing, such as gift cards. Understanding that gift cards present both an opportunity and a threat. An opportunity as they provide immediate cash flow to pay off bills or payroll in the short term, a threat because there is always the possibility the restaurant may not survive to fulfill the promise of future service to customers. Additionally, understanding that when/if those customers come to dine, the restaurant at that time will incur all the expense but not the cash flow and if operating on thin margins, like most restaurants do this could be a potential financial concern. Also, if the operation decides to start a crowdfunding type of fundraising account, knowing there could be a delay in retrieving funds to verify identity and distribution methods for the funds. Being prepared and getting ahead of the potential issue could save some unwanted stress in meeting financial deadlines. 
IHR

35,2

148

\section{Conclusion}

The purpose of this paper was to provide an analysis of the restaurant industry's response to the coronavirus pandemic during the initial onset through the easing of restrictions (March 15-May 15, 2020) to highlight effective, key operational changes should the industry experience a similar situation in the future. Through the review of industry articles and interviews with operators, three major themes were uncovered: expansion of takeout/delivery operations, innovation, and community/employee outreach, each broken down into sub-themes. In expansion of takeout/delivery operations six relevant sub-themes arose: adjusted operating schedules and employee roles, re-imagined dining rooms, new/limited/ rotating menus, online ordering/third-party delivery, collaboration and lastly communication. This section provides insights as to what some operators did to cope with and adjust to the new normal of restaurant operations prior to restrictions being lifted.

The innovation theme builds on the simple expansion of carry out/delivery operations and creates innovative ways to generate revenue, provide value to customers and stay true to their brand. Innovation was further sub-divided into five themes: pop-up market/ grocery store partnership, to-go cocktails/beer/wine, family meals/meal kits, food with a side of fun, and additional revenue streams. Lastly, the community outreach/corporate support theme which highlights the altruistic nature of the hospitality industry was divided into three sub-themes: community/employee outreach, production of hand sanitizer and lastly corporate donations/grants and funds. Despite the dire situations many found themselves in, the hospitality industry still found a way to support their employees and communities.

This systematic review of industry articles and subsequent interviews provides a foundation which other restaurants and hospitality businesses can build from in whole or in part should another pandemic or similar event which forces restaurants to close occur in the future. While there is no way to predict the future, learning from the current situation to inform our future is critical.

\section{References}

Adams, E. (2020), Some Fast-Casual Chains, Lost for the Lunch Rush, Hold Out for a Rise in Delivery Demand, Eater NY, available at: https://ny.eater.com/2020/3/23/21187704/fast-casual-chainsjunzi-mexicue-coronavirus-nyc.

AHLA (2020), COVID-19's Impact on the Hospitality Industry, American Hotel and Lodging Association, available at: https://www.ahla.com/covid-19s-impact-hotel-industry.

Alarcón, C. (2020), A Few Ways Restaurants Are Helping Others, and How You Can Help, Forbes, available at: https://www.forbes.com/sites/claudiaalarcon/2020/04/15/a-few-ways-restaurantsare-helping-others-and-how-you-can-help/ (accessed 22 June 2020).

Bellwood, O. (2020), "Home-delivered cocktails from the world's best bars", available at: https://www. thespiritsbusiness.com/2020/03/home-delivered-cocktails-from-the-worlds-best-bars/.

Canavan Dixler, H. (2020), "Restaurants permanently pivot to fast-casual, to-go, and market formats because of COVID-19 — eater", available at: https:/www.eater.com/2020/5/8/21252278/ restaurants-make-permanent-pivots-to-markets-takeout-fast-casual-because-of-covid-19pandemic.

Carruthers, N. (2020a), "Pernod to donate alcohol for hand sanitiser production", available at: https:// www.thespiritsbusiness.com/2020/03/pernod-to-donate-alcohol-for-hand-sanitiser-production/.

Carruthers, N. (2020b), "Discus aims to ease rules on hand sanitiser production", available at: https:// www.thespiritsbusiness.com/2020/03/discus-aims-to-ease-rules-on-hand-sanitiser-production/.

Carruthers, N. (2020c), "Distilleries making hand sanitiser to combat coronavirus", available at: https:// www.thespiritsbusiness.com/2020/03/distilleries-making-hand-sanitiser-to-combat-coronavirus/. 
Carruthers, N. (2020d), "Diageo donates 2m litres of alcohol for hand sanitiser", available at: https:// www.thespiritsbusiness.com/2020/03/diageo-donates-2m-litres-of-alcohol-for-hand-sanitiser/.

Carruthers, N. (2020e), "Bacardi ramps up hand sanitiser production", available at: https:/www. thespiritsbusiness.com/2020/03/bacardi-ramps-up-hand-sanitiser-production/.

Chaplin, C. (2020), "Three LA restaurants provide food to students who rely on meal programs - eater LA", available at: https://la.eater.com/2020/3/19/21186388/los-angeles-free-meals-studentscoronavirus-closures-lausd.

Dai, S. (2020), "New York restaurants can sell liquor to-go but only with food, state says — eater NY",

Restaurant industry during COVID-19 available at: https://ny.eater.com/2020/3/17/21182052/new-york-state-liquor-authorityrestaurant-laws-coronavirus.

Distilleries Making Hand Sanitizer to Fight COVID-19 (n.d.), "Distilled spirits council of the United States", available at: https://www.distilledspirits.org/distillers-responding-to-covid-19/ distilleries-making-hand-sanitizer/ (accessed 27 July 2020).

Ebner, T. (2020), Jrink Juice Bar Now Delivers Cookies and Soup Thanks to New, Local Partnerships, Eater DC, available at: https://dc.eater.com/2020/3/26/21195613/jrink-juice-bar-delivery-cookiessoup-grain-bowls-dc-logan-circle-market.

Elliott, F. (2020a), LA's Famous Apple Pan Does Delivery for First Time in 73-Year History, Eater LA, available at: https://la.eater.com/2020/3/17/21183842/apple-pan-burger-restaurant-los-angelesdelivery-75-years-news.

Elliott, F. (2020b), Orange County BBQ Spot Promises 1,500 Free Meals for Unemployed Workers, Eater LA, available at: https://a.eater.com/2020/3/19/21187438/orange-county-coronaviruscovid-19-free-food-restaurant-workers-event-heritage-barbecue.

Elliott, F. (2020c), Rad New LA Pizza Delivery Service Comes with Immersive At-Home Vampire Game, Eater LA, available at: https://la.eater.com/2020/4/7/21212367/los-angeles-coronavirus-deliverypizza-immersive-game-clues-vampires.

Elliott, F. (2020d), A Bunch of Thai Town's Best Restaurants Are Offering Menu Items for Just \$5 Right Now, Eater LA, available at: https:/la.eater.com/2020/4/13/21219346/menu-deal-thai-townlos-angeles-5-dollars-coronavirus.

Elliott, F. (2020e), Petty Cash Returns to Life with at-Home Taco Kits and \$1 Delivery Margaritas, Eater LA, available at: https:/la.eater.com/2020/4/29/21240589/morning-briefing-restaurant-news-losangeles-petty-cash-one-dollar-margaritas-delivery.

Everett, G. (2020), More than 64,000 Infected, GDP Cuts, and SARS Parallels: Here's How Bad the Global Economy Could Get as the Coronavirus Outbreak Rages | Markets Insider, Markets.Businessinsider.Com, available at: https://markets.businessinsider.com/news/stocks/ coronavirus-impact-global-economy-gdp-worstcase-scenario-us-china-2020-2-1028908366.

Fantozzi, J. (2020), Starbucks Donates \$10 Million in Grants to Employees in Need during Coronavirus Crisis, Nation's Restaurant News, available at: https:/www.nrn.com/quick-service/starbucksdonates-10-million-grants-employees-need-during-coronaviruscrisis.

Feldmar, J. (2020), After Delivery Pivot, Big-Name Restaurants Decide It's Better Just to Close, Eater, available at: https://www.eater.com/2020/4/1/21202173/coronavirus-delivery-takeout-closingandy-ricker-sqirl.

Flaherty, D. (2020), Bars and Restaurants Get Creative with Drink Sales in the Wake of Coronavirus Pandemic, Nation's Restaurant News, available at: https:/www.nrn.com/beverage-trends/barsand-restaurants-get-creative-drink-sales-wake-coronavirus-pandemic.

Fortney, L. (2020), East Village Favorite Veselka Returns for Pierogi Delivery and Takeout on Friday, Eater NY, available at: https://ny.eater.com/2020/4/29/21239669/nyc-coronavirus-veselkareopening-friday.

Gibson, A. (2020), "Hospitality heroes: chefs feeding thousands of furloughed restaurant workers nationwide", available at: https://www.forbes.com/sites/ambergibson/2020/04/02/hospitalityheroes-chefs-feeding-thousands-of-furloughed-restaurant-workers-nationwide/\#4dd4817935a5. 
IHR

35,2

Glazer, F. (2020), How Restaurants Are Catering to Families, Kids during Coronavirus, Nation's Restaurant News, available at: https:/www.nrn.com/coronavirus/how-restaurant-chains-arecatering-families-kids-during-coronavirus-pandemic.

Harris, J.D., Quatman, C.E., Manring, M.M., Siston, R.A. and Flanigan, D.C. (2014), "How to write a systematic review", The American Journal of Sports Medicine, Vol. 42 No. 11, pp. 2761-2768, doi: $10.1177 / 0363546513497567$.

He, G. (2020a), What Cocktail Delivery Actually Looks like during the Coronavirus Crisis, Eater NY, available at: https://ny.eater.com/2020/3/18/21185048/coronavirus-alcohol-delivery-nyc-photos.

He, G. (2020b), One Month into the Shutdown, Restaurants Are Boarding up Their Windows, Eater NY, available at: https://ny.eater.com/2020/4/17/21219888/nyc-restaurant-plywood-coronavirus-photos.

Hiatt, G. (2020a), Emilie's Trendy Communal Restaurant Offers Vietnamese Takeout during Coronavirus Pandemic, Eater DC, available at: https://dc.eater.com/2020/3/17/21183280/ emilies-restaurant-vietnamese-takeout-banh-mi-spring-rolls-kevin-tien-capitol-hill-dc.

Hiatt, G. (2020b), The Last Open Restaurant on Petworth's Main Drag Gets by on Whiskey and Barbecue, Eater DC, available at: https://dc.eater.com/2020/3/24/21192585/cinder-barbecuepetworth-takeout-delivery-togo-whiskey.

Hiatt, G. (2020c), Federalist Pig Runs a Fedwich Sandwich Delivery Pop-Up in Kramerbooks, Eater DC, available at: https://dc.eater.com/2020/4/15/21221209/fedwich-popup-kramerbooks-afterwordsfederalist-pig-barbecue-burgers-half-smoke-takeout-delivery.

Hiatt, G. (2020d), Top D.C. Restaurants like Bad Saint, Tail up Goat Sitting Out of Takeout during Pandemic, Eater DC, available at: https://dc.eater.com/2020/3/20/21185723/dc-restaurantsopting-out-takeout-delivery-coronavirus (accessed 24 June 2020).

Holmes, M. (2020), This LA Taco Restaurant Is Packing Toilet Paper Rolls with Takeout Orders, Eater LA, available at: https:/la.eater.com/2020/3/16/21182225/guerrilla-tacos-coronavirus-taco-kitlos-angeles-restaurants.

Hoover, M. (2020), I'm a Restaurateur and Coronavirus Forced Me to Rethink My Business Plan, Eater, available at: https:/www.eater.com/2020/3/25/21193916/martha-hoover-coronavirus-businessplan-reaction-patachou-interview.

Houck, B. (2020a), With Sanitizing-Solution Shortage, Liquor Distilleries Are Stepping Up and Making Their Own, Eater, available at: https://www.eater.com/2020/3/16/21181423/liquor-distilleriescreate-high-alcohol-proof-hand-sanitizer-to-combat-coronavirus-covid-19.

Houck, B. (2020b), America's Restaurants Are Closing. What's Happening to the Food?, Eater, available at: https://www.eater.com/2020/3/17/21181403/restaurants-combat-food-waste-amidcoronavirus-by-donating-to-food-banks.

Houck, B. (2020c), Restaurants Become Corner Stores to Stay in Business throughout the Coronavirus Pandemic, Eater, available at: https://www.eater.com/2020/3/20/21187688/restaurants-becomecorner-stores-to-survive-coronavirus-covid-19-pandemic.

Jackson, A. (2020), A Georgia Bar Owner Removed \$3,714 Worth of Bills Stapled to the Walls to Give to Her Unemployed Staff, CNN, available at: https://www.cnn.com/2020/04/08/us/sand-bar-dollarbills-donation-trnd/index.html (accessed 20 July 2020).

Japhe, B. (2020), As COVID-19 Imperils the Restaurant Industry, These Brands Are Here To Help, available at: https://www.forbes.com/sites/bradjaphe/2020/03/26/as-coronavirus-covid19ravishes-the-restaurant-industry-these-brands-are-here-to-help/\#1ae4f8266a61.

Kelso, A. (2020a), Restaurants Will Lose Business Because of the Coronavirus, But They're Stepping Up To Help Anyway, available at: https://www.forbes.com/sites/aliciakelso/2020/03/17/restaurantswill-lose-business-because-of-the-coronavirus-but-theyre-stepping-up-to-help-anyway/ \#42ed116215f5.

Kelso, A. (2020b), Some Restaurants are Transforming into Markets to Survive the Coronavirus Crisis, available at: https://www.forbes.com/sites/aliciakelso/2020/03/23/some-restaurants-aretransforming-into-markets-to-survive-the-coronavirus-crisis/\#27b44aa5583c. 
Kelso, A. (2020c), "Chick-fil-A is bringing back its meal kits for pantry-fatigued families", available at: https://www.forbes.com/sites/aliciakelso/2020/04/30/chick-fil-a-is-bringing-back-its-meal-kitsfor-pantry-fatigued-families/\#217ee3c051ac.

Kiely, M. (2020), "William Grant to make $5 \mathrm{~m}$ litres of alcohol for hand sanitiser", available at: https:// www.thespiritsbusiness.com/2020/03/william-grant-to-make-5m-litres-of-alcohol-for-handsanitiser/.

Kravitz Hoeffner, M. (2020), New York City Restaurants Are Adjusting Menus, Adding Quarantine Meals, available at: https:/www.forbes.com/sites/melissakravitz/2020/03/17/new-york-cityrestaurants-coronavirus-covid-quarantine-pandemic/\#743bd8823564.

Krishnamoorthy, A. (2020), D.C. Bars Package up Popcorn and PB\&Js to Comply with Alcohol Delivery Rules-Eater DC, available at: https://dc.eater.com/2020/3/30/21196404/dc-drink-delivery-alcoholcocktails-beer-wine-prepared-food-popcorn-peanut-butter-mayo-sandwich.

Krishnamoorthy, A. and Plumb, T. (2020), Mapping D.C. Restaurants that Sell Groceries during the Coronavirus Outbreak, Eater DC, available at: https://dc.eater.com/maps/mapping-d-crestaurants-that-sell-groceries-during-the-coronavirus-outbreak.

Krupnick, E. (2020), Restaurants Cannot Cook Their Way Out of This Crisis, Eater, available at: https://www.eater.com/2020/4/8/21212386/restaurants-coronavirus-bailout-stimulus.

Ledsom, A. (2020), "As wine producers suffer, France turns unsold wine into sanitizer", available at: https://www.forbes.com/sites/alexledsom/2020/06/05/as-wine-producers-suffer-france-turnsunsold-wine-into-sanitizer/\#30ca83c6143d.

Lee, J.W. and McKibbin, W.J. (2004), "Estimating the global economic impact of SARS", Learning from SARS: Preparing for the Next Disease Outbreak: Workshop Summary, National Academies Press (US), available at: http://www.ncbi.nlm.nih.gov/books/NBK92473/.

Lempert, P. (2020), A Grocery Store inside A Restaurant? Perhaps the New Reality of A PostCoronavirus World, Forbes, available at: https://www.forbes.com/sites/phillempert/2020/04/19/ the-restaurmart-will-be-the-new-post-covid-19-restaurant-model/.

Louise, J.Q. (2020), A Few Ways Boston Restaurants Are Giving Back, Forbes, available at: https:// www.forbes.com/sites/jqlouise/2020/03/31/a-few-ways-boston-restaurants-are-giving-back/ (accessed 22 June 2020).

Luna, N. (2020a), To Slow the Spread of Coronavirus, Taco Bell, Chick-Fil-A, Dunkin', Chipotle, Panda Express, Shake Shack, Starbucks Move to Off-Premise Only Operations, Nation's Restaurant News, available at: https://www.nrn.com/quick-service/slow-spread-coronavirus-taco-bell-chickfil-dunkin-chipotle-panda-express-shake-shack.

Luna, N. (2020b), Casual Dining Chains Face Difficult Choices: Temporarily Close and Layoff Hundreds or Bet on Curbside Pickup to Survive, Nation's Restaurant News, available at: https://www.nrn. $\mathrm{com} /$ casual-dining/casual-dining-chains-face-difficult-choices-temporarily-close-and-layoffhundreds-or.

Luna, N. (2020c), Subway Testing 'Subway Grocery' in 100 Southern California Restaurants, Nation's Restaurant News, available at: https://www.nrn.com/quick-service/subway-testing-subwaygrocery-100-southern-california-restaurants.

Luna, N. (2020d), Noodles and Company Sees Sales Improve after Adding Curbside Pickup, Nation's Restaurant News, available at: https://www.nrn.com/fast-casual/noodles-company-sees-salesimprove-after-adding-curbside-pickup-75-restaurants.

Luna, N. (2020e), Chick-fil-A Creates \$10.8 Million Relief Fund, Nation's Restaurant News, available at: https://www.nrn.com/franchising/chick-fil-creates-108-million-fund-franchisees-spend-localcommunities.

Luna, N. (2020f), Expanding Delivery Partners Is Paying off for McDonald's, Nation's Restaurant News, available at: https://www.nrn.com/quick-service/drive-thru-expanded-delivery-payingmcdonald-s-during-covid-19-pandemic. 
IHR

35,2

Luna, N. (2020g), The Rise of Contactless Ordering and Curbside Pickup amid COVID-19, Nation's Restaurant News, available at: https:/www.nrn.com/delivery-takeout-solutions/premise-risecontactless-ordering-and-curbside-pickup-amid-covid-19-offer.

Luna, N. (2020h), El Pollo Loco Triples Delivery, Online Sales During Covid-19 Pandemic, available at: https://www.nrn.com/quick-service/el-pollo-loco-triples-delivery-online-order-sales-duringcoronavirus-pandemic.

Madhav, N., Oppenheim, B., Gallivan, M., Mulembakani, P., Rubin, E. and Wolfe, N. (2017), "Pandemics: risks, impacts, and mitigation", in Jamison, D.T., Gelband, H., Horton, S., Jha, P., Laxminarayan, R., Mock, C.N. and Nugent, R. (Eds), Disease Control Priorities: Improving Health and Reducing Poverty, 3rd ed., The International Bank for Reconstruction and Development / The World Bank. available at: http://www.ncbi.nlm.nih.gov/books/NBK525302/.

Maynard, M. (2020a), "5 new ways to help your favorite restaurant survive the coronavirus crisis", available at: https://www.forbes.com/sites/michelinemaynard/2020/03/18/5-new-ways-to-helpyour-favorite-restaurant-survive-the-coronavirus-crisis/\#ffcd398266a1.

Maynard, M. (2020b), Now in New Orleans Grocery Stores: Famous Chefs Riding Out the Coronavirus, Forbes, available at: https:/www.forbes.com/sites/michelinemaynard/2020/03/24/now-in-neworleans-grocery-stores-famous-chefs-riding-out-the-coronavirus/.

Maynard, M. (2020c), "How one Chicago restaurant is staying afloat with carry-out as coronavirus leaves industry scrambling", available at: https:/www.forbes.com/sites/michelinemaynard/ 2020/04/20/restaurants-are-scrambling-to-survive-how-one-chicago-place-is-keeping-afloat-oncarry-out/\#304386b437d5.

Maynard, M. (2020d), From Fine Dining to Fast Food, Family Meals Are Restaurants' Latest Shutdown Focus, Forbes, available at: https://www.forbes.com/sites/michelinemaynard/2020/04/29/fromfine-dining-to-fast-food-family-meals-are-restaurants-latest-shutdown-focus/.

McCarron, M. (2020), How One Chef Is Feeding LA's Hospital Workers, 100 Enchiladas at a Time, Eater, available at: https://www.eater.com/2020/4/15/21219753/restaurants-feeding-hospitalworkers-covid-19-coronavirus.

McCarthy, A. (2020a), Kroger Adds Dishes from Two Beloved Houston Restaurants to its Shelves, Eater Houston, available at: https://houston.eater.com/2020/4/8/21213413/kroger-local-restaurantspartnership-kim-son-burns-original-bbq.

McCarthy, A. (2020b), James Beard Award Winner Hugo Ortega Brings His Most Popular Dishes to HEB, Eater Houston, available at: https:/houston.eater.com/2020/4/20/21228222/hugo-ortegaheb-take-and-bake-meals.

NRA (2020), Coronavirus Information and Resources, National Restaurant Association, available at: https://restaurant.org/Manage-My-Restaurant/Business-Operations/preparedness/Covid19.

O'Brien Coffey, J. (2020a), "Distilleries ramp up to produce hand sanitizer", available at: https://www. forbes.com/sites/jeanneobriencoffey/2020/03/26/distilleries-ramp-up-to-produce-hand-sanitizer/ \#561b79074e18.

O'Brien Coffey, J. (2020b), "Boston-area partnership converts beer to hand sanitizer", available at: https://www.forbes.com/sites/jeanneobriencoffey/2020/04/30/when-you-need-hand-sanitizermore-than-beer/\#3c0e5d793c62.

O'Brien Coffey, J. (2020c), "It's like starting A whole new restaurant: take out in the time of COVID-19", available at: https:/www.forbes.com/sites/jeanneobriencoffey/2020/03/24/its-like-starting-awhole-new-restaurant-take-out-in-the-time-of-covid-19/\#261ca4e62c1d.

Pershan, C. (2020a), How Fine Dining Restaurants Are Responding to Coronavirus, Eater, available at: https://www.eater.com/2020/3/13/21178890/fine-dining-restaurants-react-coronavirus-covid-19takeout (accessed 17 June 2020).

Pershan, C. (2020b), Yelp, GoFundMe Make COVID-19 Fundraisers for Restaurants without Their Permission, Eater, available at: https://www.eater.com/2020/3/27/21196593/yelp-gofundmeautomatic-fundraisers-restaurants-coronavirus-covid-19. 
Petre, H. (2020), Restaurants Pivot to Groceries and Meal Kits to Save Business during the COVID-19 Pandemic, Nation's Restaurant News, available at: https://www.nrn.com/delivery-takeoutsolutions/restaurants-pivot-groceries-and-meal-kits-save-business-during-covid-19.

Plumb, T. (2020a), Top-Flight Takeout to Consider while Dining Out Shuts Down in D.C, Eater DC, available at: https://dc.eater.com/maps/dc-restaurants-takeout-options-during-coronavirusisolation-quarantine.

Plumb, T. (2020b), D.C.'s Beer Hall-Turned-Relief Center Needs More Help from Chefs, Eater DC, available at: https://dc.eater.com/2020/3/16/21181709/dc-beer-hall-hook-hall-ramw-relief-centerrestaurant-industry-workers-coronavirus-pandemic.

Plumb, T. (2020c), The Uncaged Chefs Will Start Delivering Super Indulgent Soul Food, Eater DC, available at: https://dc.eater.com/2020/3/31/21200968/the-uncaged-chefs-brunch-brentwoodam-intel.

Plumb, T. (2020d), Pom Pom Owner Pivots to Wine Kits that Include Sexy Playlists and Lube, Eater DC, available at: https://dc.eater.com/2020/5/6/21248099/seco-wine-store-online-pivot-pompom-dosmamis-carlie-steiner-petworth.

Plumb, T. (2020e), The Salt Line Opens a To-Go Operation with Lobster Roll and Lager Combos, Eater DC, available at: https:/dc.eater.com/2020/5/12/21255041/salt-line-seafood-restaurant-reopenstakeout-delivery-oysters-navy-yard-dc.

Plumb, T. (2020f), Adams Morgan Favorite Jack Rose Returns with Takeout Packs Full of Southern Snacks, Eater DC, available at: https://dc.eater.com/2020/5/15/21258544/jack-rose-whiskey-barreopening-takeout-menu-the-imperial-bar-adams-morgan.

Ramirez, E. (2020a), "Bars, restaurants tackle coronavirus closings with to-go drinks and bottled cocktails", available at: https:/www.forbes.com/sites/elvaramirez/2020/03/21/bars-restaurantstackle-coronavirus-closings-with-to-go-drinks-and-bottled-cocktails/\#5b3675da16f1.

Redman, R. (2020), Restaurant Chain Just Salad Launches Grocery Delivery, Nation's Restaurant News, available at: https://www.supermarketnews.com/prepared-foods/restaurant-chain-just-saladlaunches-grocery-delivery.

Ruggless, R. (2020a), How Wingstop Is Growing Sales during the Pandemic, Nation's Restaurant News, available at: https://www.nrn.com/fast-casual/how-wingstop-growing-sales-during-pandemic.

Ruggless, R. (2020c), Wingstop Credits Delivery Promotion for Spike in April Same-Store Sales, Nation's Restaurant News, available at: https:/www.nrn.com/fast-casual/wingstop-credits-deliverypromotion-spike-april-same-store-sales.

Ruggless, R. (2020d), Buffalo Wild Wings to Open 'GO' Format Unit in Georgia, Nation's Restaurant News, available at: https:/www.nrn.com/casual-dining/buffalo-wild-wings-open-go-format-unitgeorgia.

Selvam, A. (2020a), Alinea Group to Temporarily Close All Restaurants in Light of State Mandates, Eater Chicago, available at: https://chicago.eater.com/2020/3/15/21180810/alinea-group-closingcoronavirus-illinois-covid-19 (accessed 23 June 2020).

Selvam, A. (2020b), EL Ideas's Philip Foss Shares How Coronavirus Affects the Restaurant, Eater Chicago, available at: https://chicago.eater.com/2020/4/7/21207541/el-ideas-douglas-parkmichelin-star-carryout-curbside-chicago-phillip-foss.

Selvam, A. (2020c), Boka to Reopen for Takeout while Stephanie Izard Debuts 'Girl and the Goat-Ceries', Eater Chicago, available at: https://chicago.eater.com/2020/4/27/21238858/boka-to-go-stephanieizard-girl-goat-ceries-takeout-open.

Selvam, A. (2020d), Independent West Town Restaurant Donates 1,000 Meals to Health Care Workers, Eater Chicago, available at: https://chicago.eater.com/2020/4/28/21239997/mott-st-feed-ourfront-lines-coronavirus-hospital-workers.

Selvam, A. (2020e), Fat Rice's Chef Goes Vegan as Restaurant Shifts to Meal Kits, Eater Chicago, available at: https://chicago.eater.com/2020/5/6/21249195/super-fat-rice-mart-abe-colonadrienne-lo-meal-kits-logan-square. 
IHR

35,2

Selvam, A. (2020f), A West Loop's Creative To-Go Package Brings Hospitality Home, Eater Chicago, available at: https://chicago.eater.com/2020/5/7/21248284/darling-to-go-west-loop-bar-packagecreative-food-drink.

Shacknai, G. (2020), For Restaurants, Go Fund Me Proves a Not-Quick-Enough Fix, Eater, available at: https://www.eater.com/2020/4/23/21228405/gofundme-restaurant-campaigns-issues-troublescoronavirus-covid-19.

Shin, C. (2020), In a City without Dine-In Customers, Restaurants Pivot to Food Relief Efforts, Eater NY, available at: https://ny.eater.com/2020/3/20/21187405/nyc-restaurants-coronavirus-relief-efforts.

Sprayregen, M. (2020), "3 restaurant owners discuss how they're coping with the COVID-19 crisis", available at: https:/www.forbes.com/sites/mollysprayregen/2020/04/09/three-restaurantowners-discuss-how-theyre-coping-through-the-covid-19-crisis/\#2333ba696856.

Sutton, R. (2020), NYC Restaurants Eleven Madison Park and Llama San Turn to High-End Auctions to Support Staff, Eater NY, available at: https://ny.eater.com/2020/3/26/21194541/elevenmadison-park-llama-san-charity-auction-nyc-restaurants-coronavirus.

Thacker, K. (2019), Growing Your Restaurant's Profit Margins $\mid$ Modern Restaurant Management $\mid$ the Business of Eating and Restaurant Management News, Modern Restaurant Management, available at: https://modernrestaurantmanagement.com/growing-your-restaurants-profitmargins/.

Thorn, B. (2020a), Full-service Restaurants Shift to Takeout, Delivery and Charity in Wake of Coronavirus Outbreak, Nation's Restaurant News, available at: https://www.restauranthospitality.com/delivery-takeout-solutions/full-service-restaurants-shift-takeout-delivery-andcharity-wake.

Thorn, B. (2020b), Shaun Garcia Adapts to Coronavirus by Offering Comfort Food to Go from Soby's, Nation's Restaurant News, available at: https:/www.restaurant-hospitality.com/people/shaungarcia-adapts-coronavirus-offering-comfort-food-go-soby-s.

Thorn, B. (2020c), Panera Bread Starts Selling Groceries in Wake of Coronavirus Pandemic, Nation's Restaurant News, available at: https://www.nrn.com/fast-casual/panera-bread-starts-sellinggroceries-wake-coronavirus-pandemic.

Thorn, B. (2020d), Andrew Gruel How the Seafood Chain Has Adjusted during Coronavirus, Nation's Restaurant News, available at: https://www.nrn.com/fast-casual/andrew-gruel-slapfishrestaurant-how-seafood-chain-has-adjusted-during-coronavirus.

Thorn, B. (2020e), Aaron Deal Tries Anything and Everything to Make Ends Meet at the River and Rail in Roanoke, Va. Nation's Restaurant News, available at: https:/www.nrn.com/people/aarondeal-tries-anything-and-everything-make-ends-meet-river-and-rail-roanoke-va.

Thorn, B. (2020f), Restaurants Profit from Looser Alcohol Regulations during Coronavirus, Nation's Restaurant News, available at: https://www.nrn.com/operations/restaurants-profit-looseralcohol-regulations-during-coronavirus-pandemic.

Troitino, C. (2020), Ditching \$135 Tasting Menus for Burgers and Bagels: How Restaurants Are Adapting to the Coronavirus, available at: https://www.forbes.com/sites/christinatroitino/2020/ 03/16/from-a-135-tasting-menu-to-burgers-and-bagels-how-the-coronavirus-is-changingrestaurants/\#4ede36ae32ae.

Turrow-Paul, E. (2020), How Restaurants Are Innovating during the COVID-19 Pandemic, available at: https:/www.forbes.com/sites/eveturowpaul/2020/03/22/how-restaurants-innovating-during-thecovid-19-pandemic/\#47541cca2c2b.

Valle, G.D. (2020), The Problem with Buying Restaurant Gift Cards Right Now, Eater, available at: https://www.eater.com/2020/5/6/21244102/the-problem-with-buying-restaurant-gift-cardsduring-coronavirus-covid-19.

Warerkar, T. (2020b), Coronavirus in NYC: USHG Auctions Weekend with HGTV's Chop and Joanna Gaines, Eater NY, available at: https://ny.eater.com/2020/5/4/21244126/chip-joanna-gaines-hgvtauction-ushg. 
Warerkar, T. (2020c), Coronavirus in NYC: Brooklyn's Olmsted Reopens as Grocery Store, Eater NY, available at: https://ny.eater.com/2020/5/11/21254620/olmsted-brooklyn-coronavirusgrocery-store.

Warerkar, T. (2020d), NYC Restaurant Taste of Persia Returns for Delivery Only during Coronavirus Crisis, Eater NY, available at: https://ny.eater.com/2020/3/30/21200386/taste-of-persia-saaedpourkay-delivery-nyc-coronavirus.

Warerkar, T. (2020e), This New Website Aggregates NYC Restaurant Gift Cards in One Place, Eater NY, available at: https://ny.eater.com/2020/3/24/21192737/nyc-restaurant-gift-card-help-mainstreet-aggregate.

Waxman, N. (2020a), Chicago Restaurants Still Have Plenty of Excellent Merch, Eater Chicago, available at: https://chicago.eater.com/2020/3/25/21193944/best-chicago-restaurant-bar-brewerymerch-clothes-accessories-sauces.

Waxman, N. (2020b), Chicago Restaurant Owners Laud Industry-Wide Resilience during Coronavirus Crisis, Eater Chicago, available at: https:/chicago.eater.com/2020/4/9/21214884/chicago-chefsrestaurant-bar-coronavirus-kaliflower-piece-brewery-pizzeria-fat-rice.

Waxman, N. (2020c), Pies from a Cult Favorite Milwaukee Bakery Are Now, Eater Chicago, available at: https://chicago.eater.com/2020/4/21/21229417/beard-and-belly-honeypie-bakery-midwestslow-food-pie-edgewater-chicago-pickup-coronavirus.

Westfall, C. (2020), Restaurant Owners Innovate to Survive as Country Reopens during Coronavirus, Forbes, available at: https:/www.forbes.com/sites/chriswestfall/2020/05/15/restaurant-ownersinnovate-to-survive-as-country-reopens-during-coronavirus/.

WHO (2010), What is a Pandemic?, World Health Organization, available at: http://www.who.int/csr/ disease/swineflu/frequently_asked_questions/pandemic/en/.

Yeo, P.K. (2020), Nine LA Restaurants Turning Their Dining Rooms Into Mini Marts, Eater LA, available at: https://a.eater.com/2020/3/25/21194495/where-to-find-pantry-grocery-restaurantslos-angeles.

Zimmerman, L.B. (2020), "How small restaurants are coping during the pandemic", available at: https:/www.forbes.com/sites/lizazimmerman/2020/05/08/how-small-restaurants-are-copingduring-the-pandemic/\#2e95a2a29078.

\section{Further reading}

Dawson, G. (2020), Kitchen United's Jim Collins on the 3 Keys to Success Right Now during the Coronavirus Pandemic, Nation's Restaurant News, available at: https://www.nrn.com/people/ kitchen-united-s-jim-collin-s-3-keys-success-right-now-during-coronavirus-pandemic.

Pivoting to off-premises (n.d.), "National restaurant association", available at: https://restaurant.org/ Articles/News/Pivoting-to-off-premises (accessed 5 May 2020).

Ruggless, R. (2020b), First Watch, after Trying Off-Premise Model, Decides to Close Units, Nation's Restaurant News, available at: https://www.nrn.com/family-dining/first-watch-after-tryingpremise-model-decides-close-units.

Warerkar, T. (2020a), Coronavirus in NYC: Restaurants Selling Merchandise to Stay Afloat, Eater NY, available at: https://ny.eater.com/2020/3/27/21192544/nyc-restaurant-merchandise-listcoronavirus-support.

\section{Corresponding author}

Cortney L. Norris can be contacted at: clnorris@central.uh.edu

For instructions on how to order reprints of this article, please visit our website:

www.emeraldgrouppublishing.com/licensing/reprints.htm

Or contact us for further details: permissions@emeraldinsight.com 